\title{
To See and to Tell: Lessing's Criticism of Ageism in The Diary of a Good Neighbor
}

\author{
Huifang LI (Corresponding author) \\ School of Foreign Studies, Hebei Normal University \\ 20 Naerhuan East Road, SJZ City, Heibei Province, China, 050024 \\ E-mail:895809192@qq.com \\ Chunrui LIU \\ School of Foreign Studies, Hebei Normal University \\ 20 Naerhuan East Road, SJZ City, Heibei Province, China, 050024 \\ E-mail:1621516823@qq.com
}

Received: December 7, 2021 Accepted: December 30, 2021 Published: December 30, 2021

doi: 10.5296/jsss.v8i2.19303

URL: https://doi.org/10.5296/jsss.v8i2.19303

\begin{abstract}
The Diary of a Good Neighbor is one of a series of works concerning age problems in the contemporary western society written by the Nobel laureate Doris Lessing. Through the record of the last days of Maudie Fowler, a ninety-two-year-old lower-class woman by a middle-aged professional Jane Somers, Lessing questions the modern social care system and criticizes the hidden social prejudice against the elderly. Lessing observes the defect of the modern social care institutions in oppressing individual choice and excluding aged people, and points out the professional service they provide cannot really comfort the aged individuals, which constructs a dilemma for both the institutions and the aged group. Different from the ageist neglect of the aged group, Lessing gives a detailed exhibition of both Maudie's daily life and her inner world, which builds a personal connection between the old and the young and draws this isolated group close to the public. Lessing also explores the taboo topic of old age, sickness and death and gives a full display of Maudie's tenacious wrestling with death, which shows the sublime of human life and challenges the ageist view of the co-decaying of spirit and body.
\end{abstract}


Keywords: The Diary of a Good Neighbor, criticism, ageism, humanism

\section{Introduction}

Doris Lessing, the 2007 Nobel Prize Laureate in literature, has a strong sense of social responsibility and has always kept a keen concern toward the disadvantaged groups in society. The Diary of a Good Neighbor was published in the year 1983 under the pseudonym Jane Summers when her fame was roaring. Together with If the Old Could..., The Grandmothers, Love, Again and An Old Woman and Her Cat, this novel focuses on the lives of the aged group, and its heroine is even older: a ninety-two-year-old woman who is approaching the end of her life. Before this novel, there had been many other works depicting old people, but none of their major characters was as old as this one. For most of us, the life of people at this age is a mystery and, to be honest, there are fewer who want to know their lives exactly. However, in an aged society, the aged has become a group that cannot be ignored, and the long-existing age discrimination has also been questioned and reflected.

Critics at home and abroad have noticed the theme of ageing in Lessing's works. In The 'Dys-Appearing' Body in Doris Lessing's The Diary of a Good Neighbor and Margaret Forster's Have the Men Had Enough? ( Oró-Piqueras, 2012), Maricel Oró-Piqueras points out people's fear and neglect of the aged bodies in modern western culture, and calls for a changing of the negative cultural connotation of the elderly. In "Gerontophobia" and the Invisible Space of Urban Life -- an Analysis of the Trans-boundary Trip in The Diary of a Good Neighbor (Lin, 2013), Lin Bin shows us the identity dilemma of the elderly women as urban marginal group, and reveals the fact that the modern instrumental rationality has suppressed the fragile human feelings. In The Writing of Aged Women in Doris Lessing's Urban Novels: a Human-Geographical Perspective (Xiao, 2021), Xiao Qinghua makes an overall analysis of the geographical space of the elderly women and discusses the emotional relationship between people and urban geography. Besides these specific discussions on the topic of ageing, some other scholars on Lessing also touched it in their research. For example, in Doris Lessing's Cultural Identity and Novel Writing (Lu, 2010), Lu Jing explores the relationship between Lessing's marginal cultural identity and her novel writing and points out the elder characters in her works, reflecting her concern for the deprived and marginalized.

However, although the scholars have applied body theory, space theory and identity theory to interpret Lessing's theme of ageing, the discussion on the reproductive ageism is not adequate. The Diary of a Good Neighbor tells a story of the friendship between two "ageing" women, one is Jane Summers, a middle-class professional in her forties, the other is Maudie Fowler, a poor working class in her nineties. From the perspective and narrative of Jane Summers, the author connects the readers with the old lady, and helps us to "recognize the subjectivity of those who are already 'older' (since age is often understood relationally) and to understand the ways in which age and ageing are culturally constructed.'(Wallace D .2011, p.389) Therefore, ageism is displayed as a dilemma in this novel which shows the self-contradiction between the modern social system and individualism. However, Doris Lessing, from her humanistic view and sound writing, questions and criticizes the western ageism which depicts aged individuals as weak, decaying and useless. 
Ageism was first put forward by Robert Butler in 1969 and refers to " a set of social relations that discriminate against older people and set them apart as being different by defining and understanding them in an oversimplified, generalized way."(Minichiello, et al., 2000, p.253) It has different manifestations such as "prejudicial attitudes toward the aged, toward old age, and toward the ageing process..., discriminatory practices against the elderly... and institutional practices and policies which... perpetuate stereotypic beliefs about the elderly, reduce their opportunities... and undermine their personal dignity." (Butler, 1980, p.8) In other words, ageism means hierarchical age relations between the old and the young, in which the younger group occupy an advantageous position and take the elderly as the "other". Therefore, ageism is age discrimination in nature. Facing the increasingly serious aging situation in the West, age discrimination has become a serious social problem.

However, unlike feminism, racism, or post-colonialism, it is difficult for the aged group to resist the social inequity because ageism has long been accepted in society, even by the old people themselves, and the "internalized ageism may prevent older people from recognizing discrimination that is based on age and may affect them personally." ( Asa B., 2019) Lessing, as a critic of her time and a woman with self-consciousness of ageing, keenly notices this problem and speaks for the discriminated old individual as well as other marginalized groups, "I have continued to oppose the methods of case studies with which human beings are classified and stamped. Each person is a marvelous mosaic of thousands of pieces. Each is unique." (Schwarzkopf, 1944, P.109) Lessing tends to care for human personality and human dignity and respect human rights of freedom either physically or mentally. With her insight and perception of the individual, Lessing pays exquisite attention to the inner world of the elderly. In The Diary of a Good Neighbor, Lessing expresses her criticism against modern ageism from the following three perspectives.

\section{The Dilemma between Individualism and Institutionalized Protection}

For most people, welfare system in western society, such as nursing homes, Home Help services and other unified government arrangements, are the best choices to provide charitable assistance to the elderly. However, Lessing sees indifference and hypocrisy in this system. The modular arrangement of the elderly is an embodiment of the industrial thinking penetrating into human society, and the purpose of it is more efficient social management and production. On the one hand, when the elderly reach a certain age, they are given a social expectation to go to the nursing home, and are virtually deprived of rights of free choices. On the other hand, they are excluded from the rich variety of social and family lives. They are treated like babies by the medical staff, but the care is entirely professional, for there is no real emotional connection between the caregivers and the elderly. Their unified and unemotional tone makes Maudie feel strange and unreal. What's more, their routine examination and other professional behavior are even more unacceptable to Maudie. Therefore, when she is dying, the professional staff couldn't give her real comfort and that is why she repeatedly asks Jane to take her home. In Maudie's view, no matter how shabby, home is a warm place where she feels free while the strange institutions are like terrible monsters. And what she expects for is a real human connection rather than the perfect service those institutions supply. So just like the madmen under Foucault, in Lessing's story, the aged 
individuals are forced to live together and being exiled from society. It might be good for resource distribution and massive production, but it sacrifices the inner feelings of the mentally healthy senior people like Maudie Fowler.

Although an old, poor lower-class woman, Maudie is strong inside. Not like most of the "obedient" old or sick people, Maudie has never given in to the hostile world. She was ill-treated by her father, her sister and her boss, but she had never really lost her conscience and judgement. She is one of the most deprived, but she never gives up her hope for love and life. She stands out like a dissenter in the silent and docile community of the aged. She dares to challenge the institutionalized ageist ideas and to stick to her own feelings.

For the ageists, old people should stay away from the world voluntarily, "Why aren't they in a Home? Get them out of the way, out of sight, where young, healthy people can't see them, can't have them on their minds!" (Lessing, 1985, p.24-25) Narrator Jane had not "seen" any old in the street for many years before she met Maudie by accident, "Ageism allows younger adults to dehumanize older adults and view older generations as a social category, a social problem, an 'other'." (Clarke, 2010, p.29) In Agewise: Fighting the New Ageism in America, Margaret Morganroth Gullette mentions the Eskimo tradition that "once it has been determined that 'old age' has set in and you can no longer contribute to the tribe and your village, you're now just taking up valuable resources for other contributing adults. So, in their tradition, you are 'pushed' out to sea where you will exit this life without being a burden." (Gullete'2011, p.29) Ageists put the elderly in a lower position and assume them without feelings and character. They believe the elderly should compromise with reality, accept their disadvantageous status and listen to the arrangements made by government and institution so as to live and leave the social stage to the creative and productive younger generation. There is no denying that for those destitute and disabled elderly, nursing homes mean protection. However, with the gradual institutionalization and industrialization of the elderly care system, this service is no longer an option but a compulsion, and the elderly who are unwilling to go to the nursing home are regarded as abnormal. But for a person with strong character like Maudie, she believes in her right to choose, hates the arrangement of those social workers and keeps saying, "You can't force me." (Lessing, 1985, p.37) The difficult situation of Maudie and the charitable social workers displays the self-contradiction between free will and the industrialized social care system and shows Lessing's humanitarian point of view.

The reason why Lessing creates such a resisting image is that she sensitively perceives that when the elderly are told they should go to a nursing home, it is in essence a deprivation of their rights of free choice, a rule of grouping under the influence of ageism, and a ruthless abandonment after being labeled "useless" by the society. It echoes Foucault's description of the prison, "The 'self-evident' character of the prison, which we find so difficult to abandon, is based first of all on the simple form of 'deprivation of liberty"' (Foucault., 1979, p.232) From Foucault's perspective, contemporary society is also a disciplinary prison network organized by social institutions, such as schools, factories, hospitals and so on. Likewise, the nursing homes also function as prisons in treating the elderly as "alien" of the society, and cutting off their social relations and separating them from the mainstream majority. Once the elderly enter the nursing home, it means they can no longer walk out of the door that marks their departure from 
younger groups. Although they have no worries about food and clothing, they seem to step on the invisible ice floe, far away from the real world. In other words, the emergence of the institutionalization of elderly care services is internalized form of ageism, symbolizing the oppression and admonishment of the dominating groups who are usually younger. As described in Madness and Civilization, at the end of the Middle Ages, leprosy and the leper disappeared from the western world, not for the poor medical practices, but for the segregation in leprosy hospitals. According to Foucault, the structures of leprosy remained, "Often, in these same places, the formulas of exclusion would be repeated, strangely similar two or three centuries later." (Foucault., 1988, p7) So nowadays, the elderly seem to become "the leper" and are sent to "nursing homes" that deprive them of their freedom, which indicates the lack of humanity. The existence of the elderly seems to be an obstacle in the development of the high-speed modern society. Therefore, in order to keep the society running at a high speed, the dominant younger put the elderly uniformly in nursing homes for standardized management and care. It is undeniable that this institutionalized service or protection, does provide material security for the elderly, but in practice, it is often blindly guided by efficiency and uniformity at the price of personality and feelings. As she has done before, Lessing again stands up to speak for the marginalized few through the ninety-two-year-old Maudie Fowler. She is sick and destitute, a perfect subject for charity and social care, but she hates social workers, hospitals and the mild and polite nurses in the care center. In the small and feeble body dwells a strong heart and persistent willpower, which shocks not only Jane, a fake "good neighbor", but also the nurses and doctors in the care center.

The so-called institutionalized protection of the elderly does not only lie within the real "walls" of nursing homes. There exist many "intangible" walls that confine the aged group in real life. The age discrimination may be dormant in all aspects. In the Diary of a Good Neighbor, a woman from the Geriatrics dressing brightly comes to Maudie's house with a professional smile on her face, " 'But, Mrs Fowler, there are so many things we could do for you, and you won't co- ...' But she dropped 'co-operate' in favor of ' ... let us." But when facing Jane, she talks " in the chummy democratic mode of our kind." (Lessing, 1985, p.38) In the Home Help services provided by the government, workers act strictly in accordance with the system, lack of humanistic care for the elderly, and replace the due "humanity" with "well-trained" focusing on efficiency. Katherine Newman, an anthropologist at Princeton, believes that "aging is at least in part a process of coming to terms with where one sits in a social hierarchy." ( Gullete, 2011, 47) Therefore, the hierarchy rules driven by ageism are reflected in the attitudes and ways of speaking to the elderly. "He said to me, Please pull up your gown, Mrs Fowler. I wasn't going to, why should I? And the nurse stepped forward, all ready to oblige, and up came my nightie, in front of them all, everything on view." (Lessing, 1985, p. 226-227) The well-trained medical team inspect and treat the elderly according to the procedures and systems. Facing the orderliness of doctors and nurses, the elderly cannot make a single decision on their own from hospitalization to treatment. Lessing describes it in detail in the novel, and reveals the age discrimination hidden behind this medical system, and shows the readers the indifference and lack of humanity of the western modern medical system towards the elderly.

In addition to the condescending attitude towards the elderly, ageism also leads to a child-like 
tone of talking when speaking to the elders, such as "eat up your pudding for me, lovie" (Lessing, 1985, p.238) or "Please lie down for me, Mrs Fowler" (Lessing, 1985, p.178), which is "the formula, insulting, used in all hospitals and Homes, by everyone working with the old, who have to be treated like small children." (Lessing, 1985, p.178) The standard terms seriously affect the self-esteem of the elderly, and they believe the trademark smile and speaking style is a disguise required by the institutionalized services. It is kind of humiliation for the elderly who have tasted the sweets and bitters of life but start to be treated like children when they are still mentally healthy. The government's "institutionalized protection" under the ageism may lead to "a fear of death being replaced by a fear of dying." (José Granero-Molina, et al., 2016) Because the elderly lose their dignity and individuality on the way to the end of their lives and become an invisible prisoner under the institutionalized system.

\section{Seeing and Talking Instead of Concealing and Isolating}

The major character and narrator Jane Summers is an editor in a fashion magazine. Before her encountering with Maudie, her life was full of delight and easiness and she spent a lot of time shopping, dressing and bathing. Of course, the delight and easiness was achieved through her shirking of responsibilities. She refused to have baby and pretended there was nothing she could do when her husband and mother were ill and dying. Like most of the younger generation, she was a refined egotist but not without conscience. Later, when she met Maudie, the most impossible person in her life, her heart was miraculously touched. This ugly, poor and arrogant old woman caught her attention and she began to visit her regularly and they gradually became real friends. Different from the social workers, Jane would have tea with Maudie and they talked, joked and quarreled with each other, which was more like an interpersonal relation rather than a charitable but stylized practice.

Through this character, Lessing unfolds the awkward life picture of the old. Following Jane's dairy, readers think about this queer old woman every day and it is also the first time that readers have known the real difficulty of aged people. It takes the elderly so much time to walk simply from bedroom to the toilet and it becomes so difficult to keep their dignity when they can neither take a bath by themselves nor control their urination and defecation. These unpleasant details were clearly depicted by Lessing, and before that, most people barely know anything of it except those nurses working in the care centre. Just as Jane experienced the illness and death of her husband and mother, for most people this part of life belongs to someone else and is none of their business. Life is a circle, and people are living with their families and friends from the very beginning of birth, the growing up, until the middle age, but when the last days come, they are forced to leave the familiar home and start another stage of life in hospitals until the last breath of life.

Under the influence of ageism, Jane had never realized the existence of the aged group before, and she tired her best to eliminate the unpleasant, unfashionable stuff from her life. Now her eyes and her ears are open to everything about the old age. With Jane's eyes and ears, Lessing let us see the weak, poor and disgraceful elderly groups in lower class represented by Maudie. What's more, she lets the ninety-two-year-old and illiterate Maudie speak and tell stories 
about her past life, and takes many pages to recall Maudie's happiness and bitterness. These recollections connect this old, decaying woman with a lively, dexterous girl and a devoted mother. The author Lessing reminds us that even this obnoxious woman had had a bright and rich life before she became so old. She had her joys and loves, accomplishments and disappointments. She is a person with a wholesome mentality as everyone of us, and what she is experiencing now will be our doom too. With this narrative technique, Lessing restores the "human" dimension of the aged and draws them back into our life and our world, and in this way, she endows them with dignity and grace.

As a woman of self-reliance and with a strong sense of self-esteem, Maudie doesn't like hospitals, "They fill you with pills and pills and pills, you feel as if your mind has been taken from you, they treat you like a child. I don't want it ..." (Lessing, 1985, p.43) She doesn't want to accept anything against her will, and bravely makes her own voice to show her resistance. When she recalls her past that the hats she made sold well and were most appreciated by her boss, she would repeat again and again, with delight, "Did I tell you how I learned to know that I was a value to her? If I did, I'll tell you again, because I love to think of it" (Lessing, 1985, p.91) She likes to talk about the days when she was creative and "useful". "Narratives for them are a key form for constructing meaning and a powerful tool for expressing and understanding subjective experiences related to living and ageing." (Lhsa, B, et al., 2021) However, in the context of ageism, a person's life meaning and value seem to be only reflected in the production of material wealth. In this logic, when people are getting old and losing their material productivity, they also lose their value and become "voiceless". In the view of ageists, the elderly should accept their fate and withdraw quietly from the central stage. Just as the electrician in Maudie's house complains, "What's the good of people that old?" " (Lessing, 1985, p.24) Another popular ageist view is that when old people lose their working ability, they become useless in every way, and they are deprived of the right to speak or influence. Just as Margaret M. Gullette has noted " the dominant cultural narrative about ageing tends to be a one-sided, linear 'decline narrative', which associates older age mainly with the loss of cognitive and physical abilities." ( O’Neill \& Schrage-Früh, 2019) This is also why Maudie cherishes her friendship with Jane so much, because she is the only one who not only helps her in life but also talks with her, and Maudie values the latter much more than the service she provides. Jane listens to her stories and shares her feelings, and she is the only one really living in her life and finding her humor, intelligence and character. Maudie gradually takes her as a family member, and wishes they could live together, whether Jane stays with her or takes her home. She misses so much the time they were together when she is in the hospital at last. There has been no writer who observe the aged mentality so closely and honestly. Even Jane, the character in the story, could not understand why the old woman has such a strong attachment for her.

Besides the observation and recording of Maudie's life by Jane, Lessing allows Maudie to speak on her own. She compares two versions of one day's life in Jane and Maudie with two chapters. We can see Jane, a lady in her forties had a very busy day and finished several tasks, while Maudie in her nineties, was also having a hard day, because she could hardly take care of herself. From this comparison, readers could go deep into Maudie's mind and find out an 
aged woman's love, hope, fear, complaints and disappointment, and realize although Maudie is decaying physically, she is still a woman with every normal feeling. In this way, Lessing expands the scope of novel and includes the aged or even the dying old into her subject, which is a clear challenge toward the ageist view which denies the value and significance of aged narrative. When the elderly began to talk, they questioned the negative cultural connotations through individual voices among which the narrative of their past lives is the expression of personal subjectivity and the affirmation of the individual values. And it helps them reconstruct their identity. For the elderly, especially for the elderly women, to talk about their joys and sorrows is an affirmation of their life experiences and a manifestation to seek and construct the meaning of their existence. For the elderly, memories about past lives are the most real and reliable thing in life and the proof of their own existence and self-worth, "Developing robust, resilient and sometimes radical stories of their lives and relationships can sustain people as they age." ( Webster-Wright, 2019) By reviewing their life stories, they can "broaden or deepen the meaning they gain from their life experiences" ( Webster-Wright, 2019), and thus rebuild their self-worth, which is the significance of speaking.

Maudie would fight against her perceived injustice through words and prove the value of her personal existence by narrating her life experiences, both of which are manifestations of the elderly trying to seek some meaning with her own voice in the society that marginalizes her. Within the context of ageism, the voices and images of the elderly are concealed, so the elderly try their best to construct the meaning of their existence in society that advocates youth. Ageism reflects in every aspect. For example, the issue of Lilith, a mainstream magazine has "Female Images" which covers all stages of a woman's life with the exception of old age: from a girl of twelve or thirteen to a married woman with a part-time job, two children, running home and husband. It seems that the scene of a person's life is dim in middle age when one begins to go downhill and withdraw from the public view. Through the voice of Jane, Lessing laments, "How afraid we are of age: how we avert our eyes!" (Lessing, 1985, p.20) Before she met Maudie, Jane was one of many ageists who could not tolerate old people due to the fear of getting old. But after encountering the tiny, bent-over old woman, after visiting her greasy and shabby house and being an audience of her narration of life, she began to understand the real state of life with purity, tenacity and toughness and realize the mediocrity of her fast-paced life. "She took one step, then paused, examined the pavement, then another step. I thought how I rushed along the pavements every day and had never seen Mrs Fowler.” (Lessing, 1985, p.13) In a youth-obsessed cultural context, everyone pursues value and speed, and the elderly are naturally ignored. Few mainstream Western literary works carry forward the elderly as the protagonist, and most of the mainstream media promote youth and beauty. The age culture makes the elderly invisible in the public view, making "getting old" itself become a synonym of "fear".

Through the portraying of the character Maudie, Lessing makes the "invisible" visible and makes the "mute" speak. She deliberately chooses this most deprived ninety-two-year-old woman as her heroine to tell us even the poorest old women have heart and guts, and their lives are filled with joys and sorrows as every one in the society, and they should be respected and accepted by the society. However, under the influence of ageism derived from 
modernism, people are treated like machines or instruments. Whenever they lose the power to produce or could not contribute to the material accumulation, they would be abandoned by the gigantic system, among which, the aged group are the most ignored and most unfairly treated. This ageism has become part of the modern culture and even the old people themselves have accepted it. They feel ashamed to ask for the care and love they deserve from their families or friends. And they become obedient subjects, choose to hide themselves from the public and wish to die peacefully like Jane's mother. However, Maudie is an exception. She is not much educated but she dares to shout out and resist, and to hope and dream. What she hopes for is a natural, real and organic human connection rather than the imposing of a cool, professional and charitable system. All her life, she keeps her pride and confidence. Perhaps, this is what Lessing tries to inform us.

\section{Unyielding Will Against the Decaying Body}

Lessing's Maudie also questions another ageist assumption that man and his body are co-decaying, which means with the corruption of their body, the aged mind will wither as well. But Maudie exhibits a human manner and the strong power of human will until the last moment, "Good God, Maudie makes such a claim on one, well or sick; such a statement does she make about herself, about life, the nature of what she has experienced." (Lessing, 1985, p.234) Maudie is extremely eager for family affection and friendship, which are more important to her than all the treating conditions in the hospital; she has a strong sense of self-esteem and could not accept being surrounded by interns as a medical case; she opposes institutionalized social treatment and social services and hopes that the people she likes and those who like her will accompany her; she is unwilling to give up her will until her death. She has never degraded herself to a pure biological sick body. "Maudie would never in her life have judged what happened to her by the physical pain she felt." (Lessing, 1985, p.245) She never surrenders herself to the institutions and always insists on independent thinking and self-reliance. Even when she couldn't take care of herself and her stomach cancer is torturing her, she refuses to take painkillers because she does not want to lose her consciousness. At the very end of her life, she still keeps a sober mind and would rather experience the real pain than play numb and dumb. In all her life, whenever facing a choice, she would listen to her heart and make a decision honestly and independently. Most people will abandon this habit when they are sick or getting old, but this stubborn little woman keeps it to the end of her life. Even the doctor is shocked by her and claims her someone unusual. Actually, she is just someone who has not been tamed by the ageist culture.

When Jane takes Maudie to visit a church, Maudie marvels at its magnificence. Some young people turn around and consider her to be abnormal. Because in the view of ageists, there is a consistency between body and spirit, and an aging body will inevitably lead to the shrinking of spirit. Therefore, when people get old, they should consciously follow the situation of their body and give up all spiritual pursuits, because their spirit is no longer useful. Maudie is different: she insists on not going to the hospital: a symbol of death and coldness. Jane's mother and husband can say frankly they have cancer, but Maudie refuses to face it. She seems to be a little "disconnected" from reality and doubtful about the society and always at a position to defend herself. She is also the one who would relax her vigilance and open her 
heart to tell life stories to her friend Jane. She won't let Jane spend time cooking for her, because she believes those trivial things will take up their time to chat together which she values so much. Maudie's value of spiritual freedom and equal treatment manifests the aging of the body does not necessarily lead to the receding of the will.

This unyielding life accompanies her until the last moment of her life. When she is forced to be hospitalized because of her advanced gastric cancer, she loses the chance to chat with Jane, which has been a biggest comfort in her life. Tormented by the physical pain in the hospital, she expresses her greatest sorry and calls her new situation a "tragedy", saying "Now that we were so happy, you coming in every evening and me telling you my stories. A tragedy this has happened ... ?" (Lessing, 1985, p.219) When her physical pain worsens and the drug given to her is a mixture of morphine and alcohol, she still refuses to give in to the decaying body or unconsciousness, and keep saying, "Lift me up, lift me." "Lift me up, lift me up!" (Lessing, 1985, p.232) M. Featherstone and M. Hepworth, the famous socialists, put forward a concept called "mask of aging", which means "the tension between external appearance .. . and the internal or subjective sense or experience of personal identity." (Katy, et al., 2020) And the elderly believe "the body that is failing them is not really theirs; in other words, their increasingly dysfunctional bodies are masking their true selves, that is, selves that are still eager to go on." ( Maricel, 2012) Therefore, Maudie would constantly fight against her weak body and violent drugs to keep herself awake. And the resistance makes her feel her internal subject has not been crushed, that her self remains intact, so she can strike back the society that discriminates against her. Lessing's portrayal of this image also aims to show that the spirit of the elderly will not die with the body. On the contrary, the life will might be at its strongest display. But thanks to the modern health care technology, this process is omitted in the name of less pain and most comfort. While in this case, the aged portrayed by Lessing does not yield to death at all and her fighting spirit is still high. Her stubborn resistance reflects the power of life in front of death. This is also a clear manifestation of Lessing's life philosophy: Face to face with life, we can understand "this is what life is all about, to feel good within ourselves and with each other and to do something we really like" with a strong power---the will to live. (Ventegodt Søren, et al., 2003)

The aged woman portrayed by Lessing has independent personality, unyielding will and the courage to express her own thoughts. Even faced with diseases and death, her desire for life is unbelievably strong, which profoundly reflects the greatness of human dignity and the efforts of the mind to transcend the body. This is not in line with what the ageist believes: With the aging of the body, the spirit and will also become worthless. Lessing characterizes such a stubborn and courageous aged woman, makes readers understand the most real state of people's lives in their twilight years, and shows the noble attitude of the elderly in the face of the collective difficulties faced by mankind - aging and death. In this way, Lessing not only expresses her praise for the glory of human life, but also criticizes the stereotyped ideas on ageing in the western society.

\section{Conclusion}

The Diary of a Good Neighbor was written by Doris Lessing when she was sixty-five years 
old which deeply reflects her sympathy and concern for the living situation of the ordinary aged group in the context of western ageism. In the novel, Lessing develops the story through the relationship between Jane Summers and Maudie Fowler. Through the description of the contemporary western society under the influence of ageism, she points out that the elderly are forced to be in a marginalized position. "The unceasingly stereotyping of older people as lonely, depressed, incompetent, disengaged, asexual, sick, senile, etc. perpetuates a hierarchical young/old binary." (Asa B., 2019) Lessing shows her deep sympathy for the elder and expresses her anti-ageism attitude through the exquisite depiction of Maudie's life and her inner world. In the novel, the social care institutions and social workers could not meet old people's need for personal attachment and social participation, and they are service providers as well as institutional oppressors, so Maudie is unsatisfied with neither of them. For a long time, the old people have been culturally marginalized, and they are invisible and mute in media and writing, but like everyone in the society, they have their feelings and hopes too. Lessing's affectionate and detailed narrative of Maudie's last days helps us see the inner world of the aged and put them back into the society. Lessing even touches the most difficult topic of death writing. Maudie shows her unusual courage and willpower in face of death in the hospital, which exhibits the ultimate dilemma of human beings: an unyielding soul and a doomed body. Lessing's questioning and criticism of the accustomed ageism in the western society signifies her humanitarian sympathy toward the aged community, and her doubts for the efficiency-first mode of modern thinking.

Supporting Agencies: China National Social Science Fund (18BWW054), Hebei Provincial Social Science Fund (HB21WW005)

\section{References}

Aagje, S. (2019). Reading ageism in "geezer and grump lit": Responses to The Secret Diary of Hendrik Groen, 83, 1/4. Journal of Aging Studies, 50.

https://doi.org/10.1016/j.jaging.2019.100794

Ann, W. W. (2019). Grace and Grit: The Politics, Poetics and Performance of Ageing as a Woman. Life Writing, 1, 96-111.

Bin, L. (2013). "Gerontophobia" and the Invisible Space of Urban Life -- an Analysis of the Trans-boundary Trip in The Diary of a Good Neighbor. Foreign Literature, 5, 29-40.

Butler, R. (1980). Ageism: A Foreword. Journal of Social Issues, 36(2), 8-11. https://doi.org/10.1111/j.1540-4560.1980.tb02018.x

Clarke, L. H. (2010). Facing age: women growing older in anti-aging culture. Rowman \& Littlefield.

Doris · Lessing. (1985) The Diaries of Jane Somers, Harper Collins Publishers Ltd, London.

Foucault, M. (1979). Discipline and Punish: The Birth of Prison. Briarpatch.

Foucault, M. (1988). Madness and Civilization : a history of insanity in the Age of Reason. Vintage Books.

Granero-Molina, J., Díaz-Cortés, M. del Mar, \& JM Hernández-Padilla, et al. (2016) Loss of 
Dignity in End-of-Life Care in the Emergency Department: A Phenomenological Study with Health Professionals. Journal of Emergency Nursing, 233-239.

https://doi.org/10.1016/j.jen.2015.10.020

Jing, L. (2010). The Cultural Identities of Doris Lessing and Her Novel Writing[J]. Nanjing Social Science, 5, 150-156.

Lhsa, B., Sv, A., \& Mm, A., et al. (2021). Stories under construction: Exploring meaning-making on a geriatric ward[J]. Journal of Aging Studies, 58.

https://doi.org/10.1016/j.jaging.2021.100940

Margaret, M. G. (2011). Agewise Fighting the New Ageism in America. Chicago \& London: the University of Chicago Press.

Margaret, O’Neill \& Michaela, S. F. (2019). Women and Ageing: Private Meaning, Social Lives. Life Writing, 16(1). https://doi.org/10.1080/14484528.2019.1532386

Margarete, von S. (1944). Placing Their Fingers on the Wounds of Our Times. In Doris Lessing: Conversations. ed. Earl G. Ingersoll. New York: Ontario Review Press.

Maricel, O. (2012). The'Dys-Appearing' Body in Doris Lessing's The Diary of a Good Neighbour and Margaret Forster's Have the Men Had Enough?[J]. Societies, 2(4), 270-285. https://doi.org/10.3390/soc2040270

Minichiello, V., Browne, J., \& Kendig, H. (2000). Perceptions and Consequences of Ageism: Views of Older People. Ageing and Society, 20(3), 253-278.

https://doi.org/10.1017/S0144686X99007710

Pilcher, K. et al. (2020). Forever "Becoming"? Negotiating Gendered and Ageing Embodiment in Everyday Life. Sociological Research Online, 25(4).

https://doi.org/10.1177/1360780420928380

Qinghua, X. (2021). The Writing of Aged Women in Doris Lessing's Urban Novels: a Human-Geographical Perspective. Social Science Research, 2, 204-212. Retrieved from https://kns.cnki.net/kcms/detail/detail.aspx ?FileName=SHYJ202102024\&DbName=CJFQ20 21

Ventegodt, S., Andersen, N. J., \& Merrick, J. (2004). Quality of life philosophy v. seizing the meaning of life and becoming well again. The Scientific World Journal, 3, 1210-1229. https://doi.org/10.1100/tsw.2003.105

Wallace, D. (2011). Literary portrayals of ageing. In An Introduction to Gerontology. ed. Lan Stuart-Hamilton. Cambridge University Press.

https://doi.org/10.1017/CBO9780511973697.014

\section{Copyright Disclaimer}

Copyright for this article is retained by the author(s), with first publication rights granted to the journal.

This is an open-access article distributed under the terms and conditions of the Creative Commons Attribution license (http://creativecommons.org/licenses/by/4.0/). 